\title{
A STUDY OF MASS-TRANSFER IN THE EXTRACTION OF IMPURITIES FROM ETHANOL AQUEOUS SOLUTION BY CARBON DIOXIDE AS A SOLVENT
}

\author{
SEIYA HIROHAMA* AND TORU TAKATSUKA \\ Chiyoda Corp., 13 Moriyacho 3-Chome, Kanagawa-ku, \\ Yokohama 221 \\ SINII MIYAMOTO AND TSUNEHISA MUTO \\ Idemitu petrochemical Co., 1-I Miyamae-cho, Tokuyama-city, \\ Yamaguchi prefecture 745
}

Key Words: Supercritical Fluid, Extraction, Mass Transfer, Ethanol, Fusel Oil

\begin{abstract}
Trace amounts of acetaldehyde, ethyl acetate, isoamyl alcohol, n-propanol and methyl ethyl ketone were effectively extracted and removed from the ethanol aqueous solution by carbon dioxide as solvent with countercurrent contractors. The experiments were carried out at 298.2 K and 7.0 MPa or 303.2 K and 7.5 MPa with solvent-to-feed ratios from 1.3 to $5.0 \mathrm{~mol} / \mathrm{mol}$. The concentration of feed ethanol aqueous solution was 20 mol\%. Packed columns with $6 \mathrm{~mm}$ Raschig rings were employed as contractors.

Although a certain amount of ethanol was dissolved into the solvent simultaneously with the trace components, the dissolved ethanol was easily recovered by scrubbing the solvent with a small amount of water.

Assuming the state of infinite dilution for each component, a simple calculational procedure was devised to determine the height per mass-transfer unit for some components in packed columns from the experimental data.
\end{abstract}

\section{Introduction}

Ethanol is an important substance in the food, chemical and pharmaceutical industries. Crude fermentation ethanol contains numerous trace components which are generated during fermentation and render the ethanol useless due to strong scent and/or reactivity. For removal of the trace components, conventional ethanol refining processes often employ extractive distillation which may lead to an increase in energy consumption.

Extraction by liquid or supercritical carbon dioxide as a solvent has potential for reducing energy consumption due to the large separation factors of trace components to ethanol ${ }^{4}$, although very few experimental works have been reported on the countercurrent extraction of trace components from ethanol aqueous solution.

The design and evaluation of the process requires not only the distribution coefficients in equilibrium but also the mass-transfer rate, which affects the height of high-pressure extractors. Although some experimental data have been reported ${ }^{1,9,11,12,13)}$ on the mass-transfer rate in the extraction of ethanol from aqueous solution, very few has been reported on the extraction of trace components.

The present work confirms the removal of trace components from ethanol aqueous solution by continuous operations with a bench-scale extractor. The height per transfer unit $(H T U)$ of the extractor is determined

* Received June 10, 1993. Correspondence concerning this article should be addressed to $\mathrm{S}$. Hirohama. from the experimental data.

\section{Experiment}

\subsection{Materials}

Ethyl acetate, acetaldehyde, isoamyl alcohol, npropanol, methanol, methyl-ethyl ketone and ethanol supplied by Wako Pure Chemical Ind. Co., Ltd. were of 98 or $99 \mathrm{vol} \%$ purity and used without further purification. Liquefied carbon dioxide supplied by Nippon Sanso Co. Ltd. was of 99.9 vol\% purity and was used without further purification.

\subsection{Apparatus}

A schematic diagram of the bench-scale test unit applied in the present work is shown in Fig. 1. The apparatus consists of an impurity extractor, a solvent-scrubbing extractor, a solvent-recovering column and feed pumps. Ethanol aqueous solution with trace components was fed into the top of the impurity extractor where the trace components and a certain amount of ethanol were extracted by carbon dioxide.

Since the amount of ethanol dissolved in carbon dioxide is lost with the extracted trace components, ethanol should be recovered from the extract. In the present work the solvent-scrubbing extractor shown in Fig. 1 was devised to recover the extracted ethanol. The effluent fiom the top of the impurity extractor was fed to the bottom of the solvent-scrubbing extractor where the 


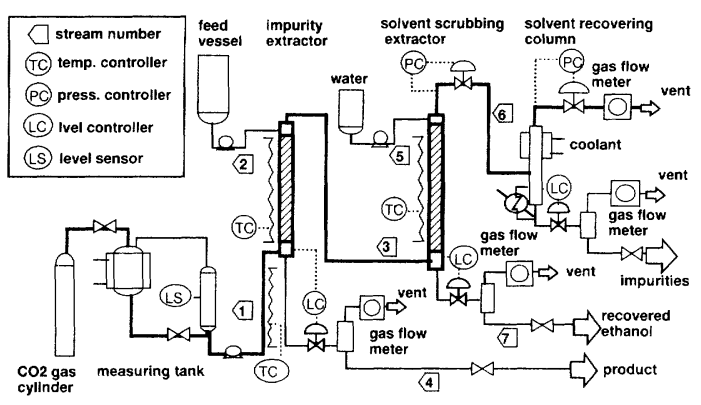

Fig. 1 Schematic diagram of experimental apparatus

Table 1. Packing characteristics

\begin{tabular}{lll}
\hline type & Raschig ring \\
material & SUS-316 \\
dimensions $\quad$ length & $6 \mathrm{~mm}$ \\
& outer diameter & $6 \mathrm{~mm}$ \\
wall & $0.4 \mathrm{~mm}$ \\
specific surface area & $722 \mathrm{~m}^{2} / \mathrm{m}^{3}$ \\
void fraction & 0.66 \\
\hline
\end{tabular}

ethanol was absorbed into a small amount of water. In a commercial plant, the recovered ethanol will be recycled to the top of the impurity extractor.

The impurity extractor has a $0.025 \mathrm{~m}$ I.D., with a 3 $\mathrm{m}$ contacting height and five redistributors. The tower contains Raschig rings whose physical characteristics are listed in Table 1. The solvent scrubbing extractor is a $0.038 \mathrm{~m}$ I.D. packed tower with a $2 \mathrm{~m}$ packing height and five redistributors with the same Raschig rings as used in the impurity extractor. Each column contains two view cells which permit observation of the interface near the top or the bottom of the tower. The position of the interface in each tower was detected by a pressure-difference sensor and was kept constant by a drain valve operated by a PID controller.

The solvent, feed, and scrubbing water were transferred by diaphragm pumps. The flow rate of the solvent was calculated from the falling rate of the level in the solvent tank. The flow rate of flue-gas streams were measured by wet test meters.

The temperature profile of each column was measured by thermocouples installed inside the column. The temperatures were controlled to a tolerance of $1.0 \mathrm{~K}$ throughout the columns by heaters operated by PID controllers. Before entering the column, the feed and the solvent were inserted into coiled tubes whose surface temperature were kept constant by heaters operated by PID controllers. Pressure in each column was measured by a pressure sensor calibrated with a dead-weight gauge and was maintained with a needle valve operated by a PID controller.

A gas chromatograph equipped with a thermal conductivity detector (TCD) was used for the composition analysis.

\subsection{Experimental conditions}

The concentrations of each trace component in the
Table 2. Result of extraction of trace components at 303.2 $\mathrm{K}, 7.5 \mathrm{MPa}$

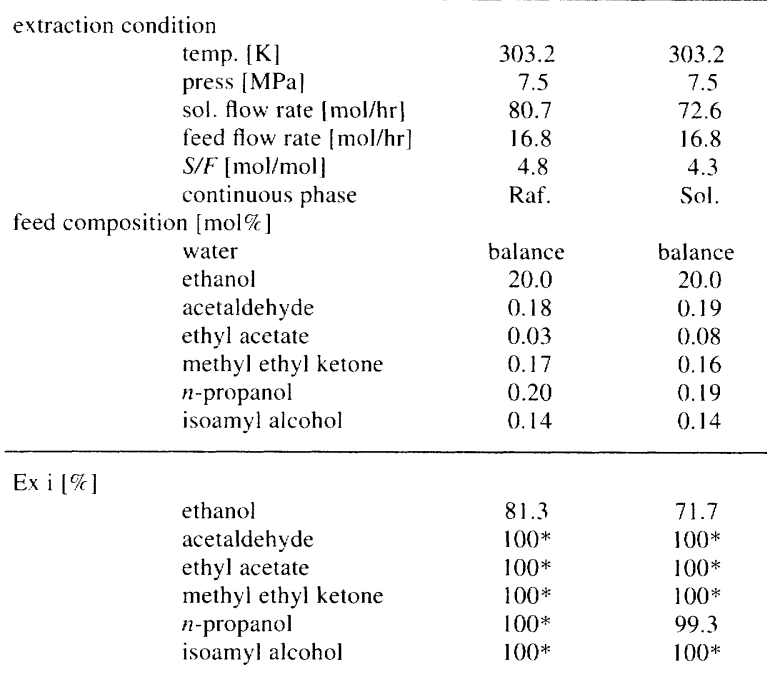

*: not detected in the raffinate by TCD

feed was set at 0.1-1.1 wt $\%$ for accuracy of composition analysis. Performance of the impurity extractor was tested when either the solvent or the raffinate was selected as the continuous phase. The extraction condition was set at $303.2 \mathrm{~K}$ and $7.5 \mathrm{MPa}$ or $298.2 \mathrm{~K}$ and 7 $\mathrm{MPa}$. The pressure was set at a slightly higher value than the saturated vapor pressure of carbon dioxide at the given temperature.

The performance of the solvent scrubbing extractor was tested at $313.2 \mathrm{~K}$ and $10 \mathrm{MPa}$ while varying the water-to-solvent ratio $(W / S)$. In the solvent-scrubbing extractor, the extract was selected as the continuous phase so as to reduce the time to reach steady state.

\subsection{Result}

1) Impurity extractor The removal ratio $\left(E_{x}\right)$ of each trace component from ethanol aqueous solutions was calculated from the experimental results by Eq. (1):

$$
E_{x, i}=\left\{1-\frac{(\text { flow rate of comp. } \mathrm{i} \text { in stream } 4[\mathrm{~mol} / \mathrm{hr}])}{\text { (flow rate of comp. } \mathrm{i} \text { in stream } 2[\mathrm{~mol} / \mathrm{hr}])}\right\} \times 100
$$

Table 2 shows the removal ratio at $303.2 \mathrm{~K}$ and 7.5 $\mathrm{MPa}$, where the temperature is slightly below the critical temperature of carbon dioxide. Almost all trace components were removed when the solvent-to-feed ratio was greater than $4.3 \mathrm{~mol} / \mathrm{mol}$.

Table 3 shows the removal ratios at $298.2 \mathrm{~K}$ and 7 $\mathrm{MPa}$, where the density of carbon dioxide is higher than that at $303.2 \mathrm{~K}$ and $7.5 \mathrm{MPa}$. Almost all of the ethyl acetate and methyl ethyl ketone in the feed were extracted when the solvent-to-feed ratio was $0.8 \mathrm{~mol} / \mathrm{mol}$, while a certain amount of $n$-propanol remained in the raffinate. When the raffinate was selected as the continuous phase the removal ratio was higher than the value observed when the extract was selected as the continuous phase. 2) Solvent scrubbing extractor The recovery ratio of 
Table 3. Result of extraction of trace components at 298.2 $\mathrm{K}, 7 \mathrm{MPa}$

\begin{tabular}{lrrrr}
\hline extraction condition & & & & \\
temp. [K] & 298.2 & 298.2 & 298.2 & 298.2 \\
press [MPa] & 7.0 & 7.0 & 7.0 & 7.0 \\
sol. flow rate [mol/hr] & 53.4 & 53.4 & 54.5 & 31.7 \\
feed flow rate [mol/hr] & 39.8 & 39.8 & 33.9 & 39.6 \\
S/F [mol/mol] & 1.3 & 1.3 & 1.6 & 0.8 \\
$\quad$ continuous phase & Sol. & Raf. & Raf. & Raf. \\
feed compositon [mol\%] & & & & \\
$\quad$ water & balance & balance & balance & baiance \\
ethanol & 20.7 & 20.7 & 20.7 & 23.2 \\
acetaldehyde & 0.0 & 0.0 & 0.27 & 0.27 \\
ethyl acetate & 0.13 & 0.13 & 0.0 & 0.0 \\
methyl ethyl ketone & 0.16 & 0.16 & 0.16 & 0.16 \\
$n$-propanol & 0.20 & 0.20 & 0.20 & 0.20 \\
isoamyl alcohol & 0.13 & 0.13 & 0.13 & 0.13 \\
\hline Ex i [\%] & & & & \\
$\quad$ ethanol & 22.8 & 28.2 & 29.1 & 17.4 \\
acetaldehyde & n.a. & n.a. & 98.8 & n.a. \\
ethyl acetate & $100^{*}$ & $100^{*}$ & $n . a$. & $100^{*}$ \\
methyl ethyl ketone & $100^{*}$ & $100^{*}$ & $100^{*}$ & $100^{*}$ \\
$n$-propanol & 39.0 & 38.9 & 48.0 & 21.3 \\
isoamyl alcohol & 91.6 & 96.7 & 99.6 & 46.3 \\
\hline HTU & & & & \\
isoumyl alcohol & 0.34 & 0.16 & 0.21 & - \\
\hline
\end{tabular}

*: not detected in the raffinate by TCD

n.a.: not available

component-i $\left(R_{x, i}\right)$, at the solvent scrubbing extractor was calculated by Eq. (2):

$$
R_{x, i}=\left\{\frac{(\text { flow rate of comp. } \mathrm{i} \text { in stream } 7[\mathrm{~mol} / \mathrm{hr}])}{(\text { flow rate of comp. } \mathrm{i} \text { in stream } 3[\mathrm{~mol} / \mathrm{hr}])}\right\} \times 100
$$

Results are shown in Table 4. More than $90 \%$ of the ethanol in stream 3 was recovered when $W / S$ was $0.3 \mathrm{~mol} /$ mol.

\section{Evaluation of $\mathrm{HTU}_{i, \mathrm{OH}}$ from the Experimental Data}

The present work developed a simple calculational procedure to predict the behavior of each trace component in the extractor assuming the state of infinite dilution. The procedure was applied to determine $H T U_{i, O H}$ from the experimental data.

\subsection{The procedure to predict $E_{x}$ and $R_{x}$}

1) The model for the extractor The following wellknown double-film model was employed to evaluate the mass-transfer rate of the column. When considering a differential slice of the extractor shown in Fig. 2, having a cross-sectional area $(A)$ and a height $(d z)$, the change of liquid-phase molar flow rate for component- $i\left(d N_{j, H}\right)$ across the slice is assumed to be expressed by the following equation, using the over-all mass-transfer coefficient $\left(k_{O H}\right)$ and the $K$-value for each component.

$$
d N_{i, H}=k_{i, O H} a_{v} A\left(\rho_{S} y_{i} / m_{i}-\rho_{H} x_{i}\right) d z
$$

where

$$
m_{i}=\rho_{S} K_{i} / \rho_{H}
$$

The material balance in the slice is:
Table 4. Recovery of ethanol from the effluent of impurity extractor by scrubbing with water

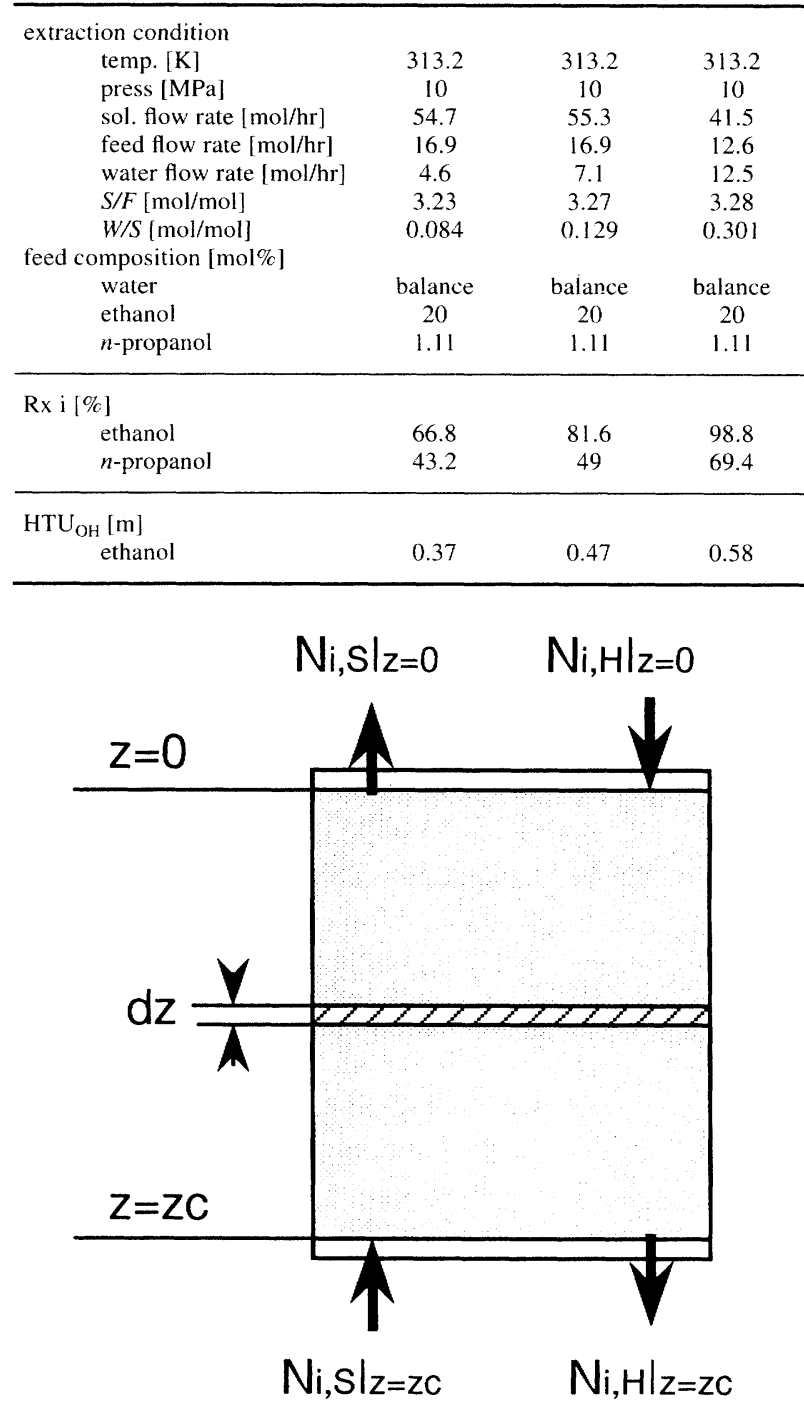

Fig. 2 Material balance of component-i in the extractor

$$
d N_{i, H}=d H_{i, S}
$$

From Eq. (4), the following equation is obtained.

$$
N_{i, S}=\left.N_{i, S}\right|_{z=z c}+N_{i, H}-\left.N_{i, H}\right|_{z=z c}
$$

Substitution of Eq. (5) to Eq. (3) yields:

$$
H T U_{i, O H} \frac{d H_{i, H}}{d z}=\left(\lambda_{i}-1\right) N_{i, H}-\lambda_{i} N_{i, S}-\left.\lambda_{i} N_{i, H}\right|_{i=z}
$$

where

$$
\begin{gathered}
\lambda_{i}=N_{T, H} / K_{i} N_{T, S} \\
H T U_{i, O H}=N_{T, H} /\left(\rho_{H} k_{i, O H} a_{v} A\right)
\end{gathered}
$$

and

$$
1 / k_{i, O H}=1 / k_{i, H}+1 /\left(m_{i} k_{i, S}\right)
$$

Since the concentration of trace component is small, the 
Table 5. Physical properties used in the present work

\begin{tabular}{|c|c|c|c|}
\hline $\begin{array}{l}\text { Temperature }[\mathrm{K}] \\
\text { Pressure }[\mathrm{MPa}] \\
\text { Location }\end{array}$ & $\begin{array}{c}313.2 \\
10 \\
\text { Solvent scrubbing } \\
\text { extractor }\end{array}$ & \multicolumn{2}{|c|}{ Impurity extractor } \\
\hline $\begin{array}{l}\text { Solvent phase } \\
\text { density }\left[\mathrm{kg} / \mathrm{m}^{3}\right] \\
\text { viscosity }[\mathrm{kg} / \mathrm{ms}] \\
\text { diffusion coef. }\left[\mathrm{m}^{2} / \mathrm{s}\right] \\
\text { ethanol } \\
n \text {-propanol } \\
\text { isoamyl alcohol }\end{array}$ & $\begin{array}{c}640 \\
5.00 \times 10^{-5} \\
\\
2.31 \times 10^{-8} \\
1.99 \times 10^{-8} \\
1.59 \times 10^{-8}\end{array}$ & $\begin{array}{l}- \\
- \\
-\end{array}$ & $\begin{array}{c}560 \\
6.30 \times 10^{-5} \\
\\
1.77 \times 10^{-8} \\
1.53 \times 10^{-8} \\
1.22 \times 10^{-8}\end{array}$ \\
\hline \multicolumn{4}{|l|}{$\begin{array}{l}\text { Parameters for Eq. }(10) \\
\text { carbon dioxide }\end{array}$} \\
\hline $\begin{array}{l}\text { A } \\
\text { B }\end{array}$ & $\begin{array}{c}2.57 \\
-3.74\end{array}$ & $\begin{array}{c}2.81 \\
-3.85\end{array}$ & $\begin{array}{c}2.83 \\
-4.00\end{array}$ \\
\hline $\begin{array}{r}\text { ethanol } \\
\text { A } \\
\text { B }\end{array}$ & $\begin{array}{c}-2.78 \\
1.08\end{array}$ & $\begin{array}{c}-2.96 \\
1.43\end{array}$ & $\begin{array}{c}-2.90 \\
1.51\end{array}$ \\
\hline $\begin{array}{l}\text { water } \\
\qquad \begin{array}{l}\mathrm{A} \\
\mathrm{B}\end{array}\end{array}$ & $\begin{array}{c}-6.33 \\
4.96\end{array}$ & $\begin{array}{c}-6.66 \\
5.26\end{array}$ & $\begin{array}{c}-6.65 \\
5.49\end{array}$ \\
\hline \multicolumn{4}{|c|}{$\begin{array}{l}\text { Raffinate phase } \\
\text { representative concentration of ethanol ( } \mathrm{mol} \% \mathrm{CO}_{2} \text {-free basis) }\end{array}$} \\
\hline $\begin{array}{l}\text { density }\left[\mathrm{kg} / \mathrm{m}^{3}\right] \\
\text { viscosity }[\mathrm{kg} / \mathrm{ms}] \\
\text { diffusion coef. }\left[\mathrm{m}^{2} / \mathrm{s}\right]- \\
\text { ethanol } \\
n \text {-propanol } \\
\text { isoamyl alcohol }\end{array}$ & $\begin{array}{c}8 \\
970 \\
6.90 \times 10^{-4} \\
\\
1.81 \times 10^{-9} \\
1.56 \times 10^{-9} \\
1.25 \times 10^{-9}\end{array}$ & $\begin{array}{l}- \\
-\end{array}$ & $\begin{array}{c}18 \\
990 \\
7.88 \times 10^{-4} \\
1.73 \times 10^{-9} \\
1.51 \times 10^{-9} \\
1.21 \times 10^{-9}\end{array}$ \\
\hline surface tenslon $[\mathrm{N} / \mathrm{m}]$ & 0.015 & - & 0.011 \\
\hline
\end{tabular}

total molar flow rates $\left(N_{T, H}\right.$ and $\left.N_{T, S}\right)$ are approximated by the sum of the molar flow rates of carbon dioxide, ethanol and water. $K$-values for carbon dioxide, ethanol and water are estimated by the following correlation:

$$
\ln \left(K_{i}\right)=A_{i}+B_{i} x_{\text {ethanol }}^{\mathrm{CO}_{2} \text { free }}
$$

The values of parameters for Eq. (10) are determined by fitting them to the $K$-values predicted by a correlation model previously proposed by the authors ${ }^{5)}$ and listed in Table 5. The model correlates the phase equilibria for the carbon dioxide-ethanol-water system closely with experimental data $\left.{ }^{7}, 10,18\right)$. The $K$-value for each trace component is obtained by multiplying that of ethanol and the separation factors computed by the empirical correlation proposed in a previous paper ${ }^{4)}$.

2) The proposed procedure By solving Eq. (6) with the $K$-values simultaneously, the composition profile for each phase throughout the extractor can be predicted. But the equations cannot be solved analytically since the $K$-values and liquid flow rate can change significantly throughout the column. In the present work Eq. (6) was solved numerically using the orthogonal collocation method $^{2)}$. The following equation is derived from Eq. (6) as shown in Appendix 1.

$$
\left(\begin{array}{c}
\left.N_{i, H}\right|_{z=z 2} \\
\left.N_{i, H}\right|_{z=z 3} \\
\vdots \\
\left.N_{i, H}\right|_{z=z c}
\end{array}\right)=\left(\boldsymbol{H}^{*}\right)^{-1}\left(\begin{array}{c}
\left.\lambda_{i}\right|_{z=z 2},-h_{2,1} \\
\left.\lambda_{i}\right|_{z=z 3},-h_{3,1} \\
\vdots \\
\left.\lambda_{i}\right|_{z=z c},-h_{n s, 1}
\end{array}\right)\left(\begin{array}{c}
\left.N_{i, S}\right|_{z=z} \\
\left.N_{i, H}\right|_{z=0}
\end{array}\right)
$$

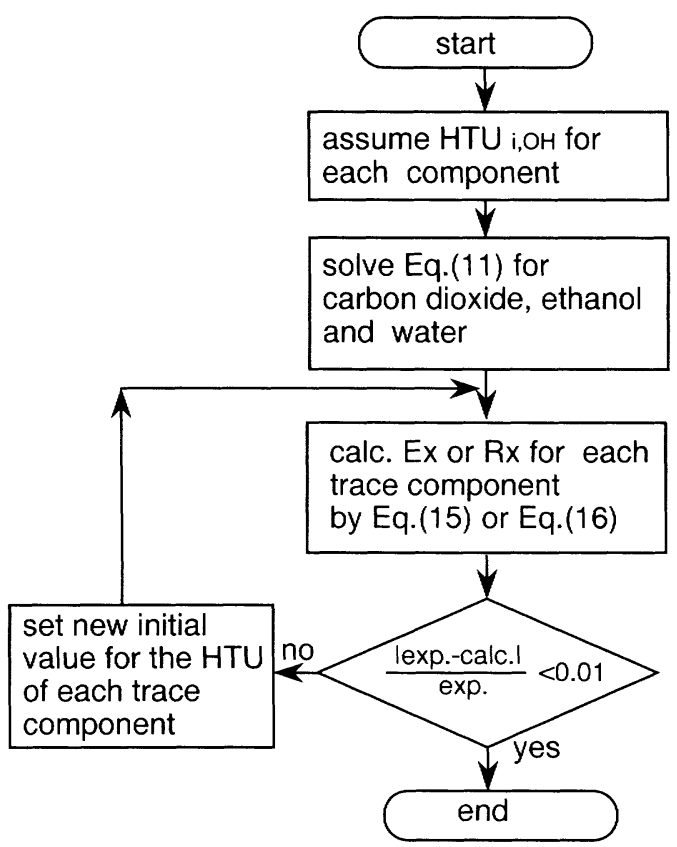

Fig. 3 Procedure proposed in the present work

where

$$
\boldsymbol{H}^{*}=\left(\begin{array}{c}
h_{2,2}, h_{2,3}, \cdots, h_{2, n s} \\
h_{3,2}, h_{3,3}, \cdots, h_{3, n s} \\
\vdots \\
h_{n, 2}, h_{n, 3}, \cdots, h_{n, n s}
\end{array}\right)
$$

and $h_{j i}$ is the element of matrix $\boldsymbol{H}$ defined by Eq. (A-9).

The $h_{j i}$ and $\lambda_{i}$ values depend on the composition and total molar flow rates of the raffinate and the solvent but are independent of the concentrations of trace component due to the assumption of the state of infinite dilution. Equation (11) should be solved by iterative calculation for the flow rates of carbon dioxide, ethanol and water.

The following equation is derived from Eq. (11).

$$
\left(\begin{array}{c}
\left.N_{i, S}\right|_{z=0} \\
\left.N_{i, H}\right|_{z=z c}
\end{array}\right)=\boldsymbol{B}\left(\begin{array}{l}
\left.N_{i, S}\right|_{z=z c} \\
\left.N_{i, H}\right|_{z=0}
\end{array}\right)
$$

where

$$
\boldsymbol{B}=\left(\begin{array}{c}
1-\sum_{j=1}^{n s-1} w_{n s-1, j} \lambda_{j+1}, 1+\sum_{j=1}^{n s-1} w_{n s-1, j} h_{j+1} \\
\sum_{j=1}^{n s-1} w_{n s-1, j} \lambda_{j+1},-\sum_{j=1}^{n s-1} w_{n s-1, j} h_{j+1}
\end{array}\right)
$$

and $w_{j i}$ is an element of matrix $\left(\boldsymbol{H}^{*}\right)^{-1}$.

Matrix $B$ represents the effect of the inlet to the column $\left(N_{i, S} S_{z=z c}\right.$ and $\left.N_{i, H} \mathrm{l}_{z=0}\right)$ on the outlet from the column $\left(\left.N_{i, S}\right|_{z=0}\right.$ and $\left.\left.N_{i, H}\right|_{z=z c}\right)$ under steady state. The value of $\boldsymbol{B}$ depends on the composition profile and total molar flow rates of the solvent phase and the raffinate.

But $\boldsymbol{B}$ is independent of the concentrations of trace components due to the assumption of infinitely dilute state. Once the profile of molar flow rates of carbon dioxide, ethanol and water are obtained by solving Eq. 


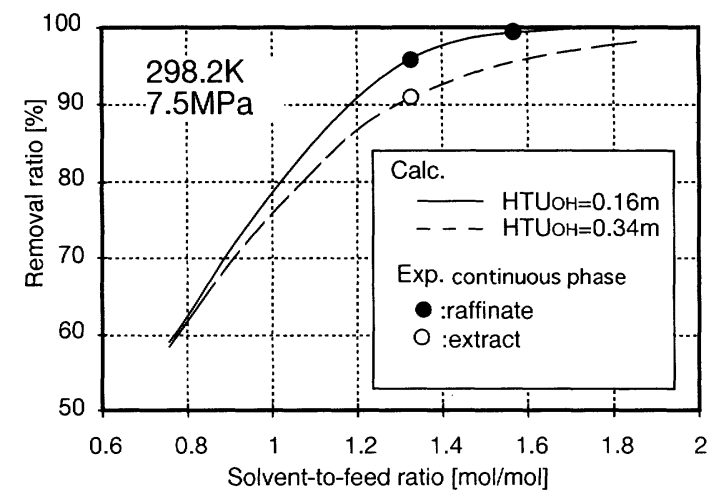

Fig. 4 Effect of solvent-to-feed ratio on the recovery ratio

(11), $\boldsymbol{B}$ for each trace component can be fixed. The molar flow rate of each trace component in the effluent from the column can be calculated by Eq. (13) without an iterative procedure. When the flow rate of component $i$ is zero in the solvent, the removal ratio for component $-i$ can be derived from Eq. (13) as follows.

$$
E_{x, i}=\frac{\left.N_{i, S}\right|_{z=0}}{\left.N_{i, H}\right|_{z=0}}=1+\sum_{j=1}^{n s-1} w_{n s-1, j} h_{j+1} \text { when }\left.N_{i, S}\right|_{z=z c}=0
$$

Similarly, the recovery ratio for component $-i$ in the solvent scrubbing extractor becomes:

$$
R_{x, i}=\frac{\left.N_{i, H}\right|_{z=z c}}{\left.N_{i, S}\right|_{z=z c}}=1+\sum_{j=1}^{n s-1} w_{n s-1, j} h_{j+1} \text { when }\left.N_{i, H}\right|_{z=0}=0
$$

\section{2 $H T U_{\mathrm{i}, \mathrm{OH}}$ determined from the experimental data}

$H T U_{i, O H}$ for each trace component was determined by solving Eq. (15) and (16) for $H T U_{i, O H}$ as shown in Fig. 3, assuming the $H T U_{i, O H}$ to be constant throughout the column. The results are listed in Tables 3 and 4 . When the removal ratio is less than $60 \%$, it is difficult to determine $H T U_{i, O H}$ since the effect of the change of $H T U_{i, O H}$ on the removal ratio is small, as shown in Fig. 4. The $H T U_{i, O H}$ value was determined only when $E_{x}$ is greater than $60 \%$. The same criterion was set for the recovery ratio. The $H T U_{i, O H}$ of $i s o a m y l$ alcohol determined in the present work was 0.16-0.34 m and was similar to the value of isopropanol proposed by Rathkamp et $a l .{ }^{15)}$ for Raschig rings, although the composition of feed is greatly different.

The values of $H T U_{i, O H}$ were predicted using Seibert and Fair's method ${ }^{17)}$ and they agreed fairly well with those determined from the experimental data as shown in Fig. 5. Physical properties used in the present work are estimated as shown in Appendix 2 and are listed in Table 5. Seibert and Fair's method also predicted that $H T U_{i, O H}$ decreases by changing the continuous phase from the extract to the raffinate. This phenomenon can be attributed to the larger hold-up of dispersed phase due to the low terminal velocity caused by the higher viscosity of the raffinate. Seibert and Fair's method can be a candidate model for use in the design of

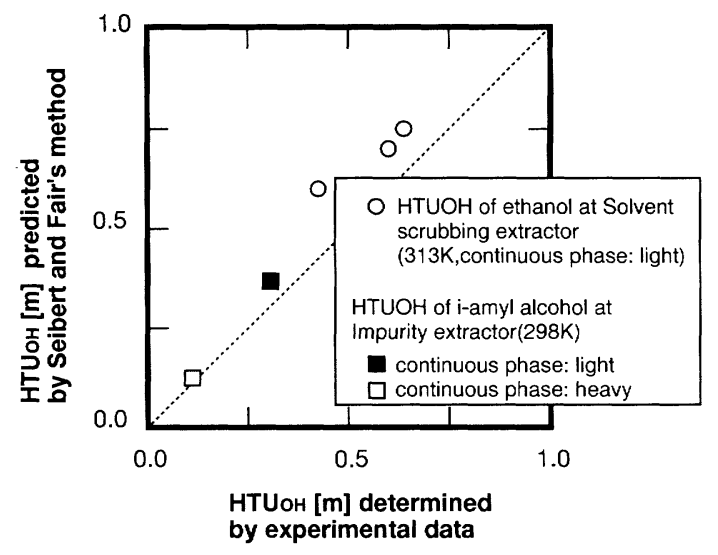

Fig. 5 Comparison of experimental and predicted $\mathrm{HTU}_{\mathrm{O}, \mathrm{H}}$

commercial plants, although evaluation of the method requires further experimental work on both $\mathrm{HTU}_{i, \mathrm{OH}}$ and the physical properties.

\section{Conclusions}

Trace amounts of acetaldehyde, ethyl acetate, isoamyl alcohol, $n$-propanol and methyl ethyl ketone were efficiently removed from the ethanol aqueous solution by the liquid carbon dioxide as solvent at temperatures slightly below its critical temperature. Although a certain amount of ethanol was dissolved into the solvent simultaneously, the dissolved ethanol was easily recovered by scrubbing the solvent with a small amount of water.

$H T U_{O, H}$ of some components in packed columns were determined from the experimental data by a simple calculational procedure devised by assuming the state of infinite dilution of each component.

Appendix 1 Solving Eq. (6) by the orthogonal collocation method ${ }^{2)}$ A polynomial approximation of $N_{i, H}$ is given as follows.

$$
N_{i, H}=b_{1}+b_{2} z_{r}+b_{3} z_{r}^{2}+\cdots+b_{n s} z_{r}^{n s-1}
$$

Differentiation of Eq. (A-1) in respect to $z_{r}$ yields

$$
\frac{d N_{i, H}}{d z_{r}}=b_{2}+2 b_{3} z_{r}+\cdots+(n s-1) b_{n s} z_{r}^{n s-2}
$$

Since Eqs. (A-1) and (A-2) stand at collocation points, the following equation can be derived.

$$
\frac{d \boldsymbol{N}_{i, H}}{d z_{r}}=\boldsymbol{A} \boldsymbol{N}_{i, \boldsymbol{H}}
$$

where

$$
\begin{aligned}
N_{i, H} & =\left(\begin{array}{c}
\left.N_{i, H}\right|_{z=0} \\
\left.N_{i, H}\right|_{z=z 1} \\
\vdots \\
\left.N_{i, H}\right|_{z=z c}
\end{array}\right) \\
\boldsymbol{A} & =\left(\begin{array}{c}
0,1,2 z_{r, 1}, \cdots,(n s-1) z_{r, 1}^{n s-2} \\
0,1,2 z_{r, 2}, \cdots,(n s-1) z_{r, 2}^{n s-2} \\
\vdots \\
0,1,2 z_{r, n s}, \cdots,(n s-1) z_{r, n s}^{n s-2}
\end{array}\right)\left(\begin{array}{c}
0, z_{r, 1}, z_{r, 1}^{2}, \cdots, z_{r, 1}^{n s-1} \\
0, z_{r, 2}, z_{r, 2}^{2}, \cdots, z_{r, 2}^{n s-1} \\
\vdots \\
0, z_{r, n s}, z_{r, n s}^{2}, \cdots, z_{r, n s}^{n s-1}
\end{array}\right)^{-1}
\end{aligned}
$$

$\left(z_{r, 1}, z_{r, 2}, \ldots, z_{r, n s}\right)$ are collocation points between 0 and 1 where $\left(z_{r, 1}=\right.$ 
$\left.0, z_{r, n s}=1\right)$ are assumed.

Differentiation in Eq. (6) can be replaced by the following equation, using matrix $\boldsymbol{A}$.

$$
\frac{d \boldsymbol{N}_{i, H}}{d z}=\boldsymbol{A} N_{i, H} / z c
$$

Substitution of Eq. (A-5) to Eq. (6) yields:

$$
H T U_{i, O H} \frac{A N_{i, H}}{z c}=\left(\boldsymbol{\lambda}_{i}-\boldsymbol{I}\right) \boldsymbol{N}_{i, H}+\left.\boldsymbol{\lambda}_{i} \boldsymbol{N}_{i, S}\right|_{z=z c} \boldsymbol{\eta}-\boldsymbol{\lambda}_{i} \boldsymbol{\gamma} \boldsymbol{N}_{i, H}
$$

where

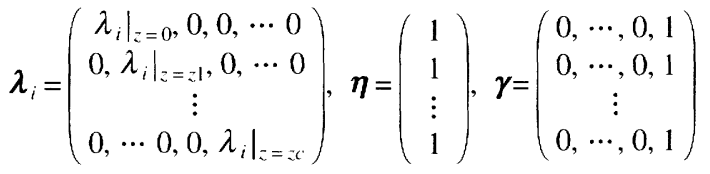

Solving Eq. (A-6) for $N_{i, H}$, the following equation is obtained.

$$
\boldsymbol{H} \boldsymbol{N}_{i, H}=\left.\boldsymbol{\lambda}_{i} N_{i, s}\right|_{z=z c} \boldsymbol{\eta}
$$

where

$$
\boldsymbol{H}=H T U_{i, O H} \frac{\boldsymbol{A}}{z c}-\left(\boldsymbol{\lambda}_{i}-\boldsymbol{I}\right)+\lambda_{i} \boldsymbol{\gamma}
$$

Solving Eq. (A-8) for $N_{i, H} \mathrm{l}_{z}=z, \ldots, N_{i, H_{z}} \mathrm{l}_{z}=z_{i}$ gives Eq. (11).

\section{Appendix 2 Estimation of physical properties}

Since the concentration of ethanol, water and trace components was minimal in the light phase (liquid or supercritical fluid), the density and viscosity of the light phase were approximated by the value for pure carbon dioxide. The density of carbon dioxide was computed by a 21 constant modified B.W.R. equation of state proposed by Huang et $a l^{6)}$ which could predict the density with enough accuracy even in the vicinity of the critical point of carbon dioxide. The viscosity of carbon dioxide was estimated by the method of Jossi et al. ${ }^{8)}$

The density of the raffinate was estimated by the Patel-Teja ${ }^{13)}$ equation of state with the mixing rule proposed by the authors ${ }^{5)}$. The viscosity of the heavy phase was estimated by the following equation.

$$
\ln (\mu)=\Sigma \ln \left(\mu_{i}^{O}\right) x_{i}
$$

The viscosity of each pure liquid at the same temperature $\left(\mu_{i}^{O}\right)$ was estimated by Andre's equation using the parameter values listed by Reid et al. ${ }^{16)}$

The diffusion coefficients were estimated by Wilke-Chang's equation $^{20)}$. An empirical factor of 0.87 was applied to the predicted values for the diffusion coefficients in the light phase. The factor was obtained by Paulaitis et al. ${ }^{14)}$, comparing the results of the Wilke-Chang's equation $^{20)}$ with published values of diffusion coefficient for organic components in supercritical carbon dioxide.

Although the data for surface tension for the carbon dioxide-water system exists, there is no data for the carbon dioxide-ethanol-water ternary system at 7-10 MPa. It is well known that the surface tension of ethanol aqueous solution decreases as the concentration of ethanol increases under ambient conditions. The present work presumed that the surface tension decreases as the concentration of ethanol in the heavy phase increases as expressed by the following equation. where

$$
\sigma_{\text {ethanol aq. } \mathrm{CO}_{2}}=\sigma_{\mathrm{H}_{2} \mathrm{O}, \mathrm{CO}_{2}}\left(\sigma_{\text {ethanol aq., air }} / \sigma_{\mathrm{H}_{2} \mathrm{O} \text {, air }}\right)
$$

$$
\left(\sigma_{\text {ethanol aq, air }} / \sigma_{\mathrm{H}_{2} \mathrm{O} \text {, air }}\right)=1-0.154 \ln \left(1+134.2 x_{\text {ethanol }}^{\mathrm{CO}_{\text {free }}}\right)
$$

and

$$
\sigma_{\mathrm{H}_{2} \mathrm{O}, \mathrm{CO}_{2}}=22 \times 10^{-3} \mathrm{~N} / \mathrm{m}
$$

When the concentration of ethanol in the heavy phase is $8 \mathrm{~mol} \%$, Eq (A-11) yields the value of $14 \times 10^{-3}, \mathrm{~N} / \mathrm{m}$ which is closed to the surface tension obtained by Lahiere et al. ${ }^{12)}$ by back-calculation from the drop diameter.

Although the concentration of ethanol in the heavy phase changes significantly in each column, the representative value of the ethanol concentration listed in Table 5 for the column was used for the above prediction of $H T U_{i, O H}$ for simplicity. The representative values were approximated by averaging the concentrations at top and bottom of columns.

\section{Acknowledgment}

We wish to thank the Ministry of International Trade and Industry (MITI) of Japan and the Japan Alcohol Association for their support and approval of the publication of this paper.

\section{Nomenclature}

$\boldsymbol{A} \quad=$ matrix defined by Eq. (A-4)

$A \quad=$ cross-sectional area of the extractor $\quad\left[\mathrm{m}^{2}\right]$

$A_{i} \quad=$ parameter of Eq. (5)

$a_{\mathrm{v}} \quad=$ interfacial area $\quad\left[\mathrm{m}^{2} / \mathrm{m}^{3}\right]$

$B_{i} \quad=$ parameter of Eq. (5) [-]

$B \quad=$ matrix defined by Eq. (14)

$b_{i} \quad=$ parameter for Eq. $(\mathrm{A}-1)$

$D_{i} \quad=$ molecular diffusion coefficient $\quad\left[\mathrm{m}^{2} / \mathrm{s}\right]$

$E x_{i} \quad=$ removal ratio of component $-i$ in the impurity extractor

$\boldsymbol{H} \quad=$ matrix defined by Eq. (A-9)

$\boldsymbol{H}^{*} \quad=$ matrix defined by Eq. (12)

$h_{i j} \quad=$ element of matrix $\boldsymbol{H}$

$H T U_{i, O H}=$ Overall height per mass-transfer unit based on heavy liquid phase for component $-i$

I $=$ elemental matrix

$K_{i} \quad=\left(=y_{i} / x_{i}\right) K$-value for component- $i$

$k_{\mathrm{OH}} \quad=$ overall mass-transfer coefficient based on heavy liquid phase

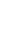
]

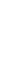
[-]

$R x \quad=$ recovery ratio at the solvent-scrubbing extractor $[-]$

$S \quad$ solvent flow rate $[\mathrm{mol} / \mathrm{hr}]$

$\begin{array}{llr}T & =\text { temperature } & {[\mathrm{K}]}\end{array}$

$W \quad$ = water flow rate $[\mathrm{mol} / \mathrm{hr}]$

$w_{i j} \quad=$ element of matrix $\left(\boldsymbol{H}^{*}\right)^{-1} \quad[-]$

$x_{i} \quad=$ mole fraction in the raffinate $[-]$

$y_{i} \quad=$ mole fraction in the solvent $\quad[-]$

$z \quad=$ distance from top of column [m]

$z_{r} \quad=z_{r}=z / z_{c} \quad[-]$

$z_{c} \quad=$ column length $\quad[\mathrm{m}]$

$\alpha_{i j} \quad=$ separation factor $\left(=K / K_{j}\right)$

$\gamma \quad=$ matrix defined in Eq. $(\mathrm{A}-7)$

$\eta \quad=$ matrix defined in Eq. (A-7)

$\lambda \quad=$ parameter defined in Eq. (7) [-]

$\lambda \quad=$ matrix defined in Eq. (A-7) $[-]$

$\mu \quad=$ vlscoslty $\quad[\mathrm{kg} / \mathrm{ms}]$

$\rho \quad=$ density $\quad[\mathrm{mol} / \mathrm{L}]$

$\begin{array}{lll}\sigma & =\text { interfacial tension } & {[\mathrm{N} / \mathrm{m}]}\end{array}$

$<$ Subscripts $>$

$$
\begin{array}{ll}
H & =\text { raffinate } \\
i & =\text { component identification number } \\
j & =\text { component identification number } \\
L & =\text { liquid phase } \\
S & =\text { solvent } \\
T & =\text { total }
\end{array}
$$

\section{$<$ Superscripts $>$}

$\mathrm{CO}_{2}$ free $=$ carbon dioxide-free basis

$$
\text { o } \quad=\text { pure substance }
$$

\section{Literature Cited}

1) Bernad, L., A. Keller, D. Barth and M. Perrut: Proceedings of 2nd International Conference for Supercritical Fluid, 394-397 (1991)

2) Finlayson, B.A.: "The Method of Weighted Residual and 
Variational Principles", 1st ed., pp. 105-120, Academic Press, New York (1972)

3) Gilbert, M.L. and M.E. Paulaitis: J. Chem. Eng. Data, 31 .296298 (1986)

4) Hirohama, S., T. Takakatsuka, S. Miyamoto and T. Muto: $J$. Chem. Eng. of Japan, 26, 247-253 (1993)

5) Hirohama, S., T. Takakatsuka, S. Miyamoto and T. Muto: $J$. Chem. Eng. of Japan, 26, 408-415 (1993)

6) Huang, F., M. Li, L.L. Lee, K.E. Starling and F.T. Chung: $J$. Chem. Eng. Japan, 18, 490-496 (1985)

7) Inomata, H., K. Arai, A. Kondo and S. Saito: J. Chem. Eng. Japan, 23, 199-207 (1990)

8) Jossi, J.A., L.I. Stiel and G. Thodos: AIChE J., 8, 59-63 (1962)

9) King, M.B., K. Kasssim and T.R. Bott: Fluid Phase Equilibria, 10, 249 (1983)

10) Kuk, M.S. and J.C. Montagna: "Chemical Engineering at Supercritical Fluid Conditions", Ed. M.E. Paulaitis, J. Penninger, R. Grang and P. Davidson, pp. 101-111, Ann Arbor Science (1983)
11) Lahiere, R.J., J.L. Humphrey and J.R. Fair: Separation science and technology, 22, 379-393 (1987)

12) Lahiere, R.J. and J.R. Fair: Ind. Eng. Chem. Res., 26, 2086-2092 (1987)

13) Patel, N.C. and A.S. Teja: Chem. Eng. Sci., 37, 463-473 (1982)

14) Paulaitis, M.E., V.J. Krukonis, R.T. Kurnik and R.C. Reid: Rev. Chem. Eng., 1, 179-250 (1983)

15) Rathkamp, P.J., J.L. Brovo and J.R. Fair: Solvent Extraction and Ion Exchange, 5 (3), 367-391 (1987)

16) Reid, C.R., J.M. Prausnitz and B.E. Poling: "The Properties of Gases and Liquids", 4th ed., pp. 656-732, McGraw-Hill, New York (1987)

17) Seibert, A.F. and J.R. Fair: Ind. Eng. Chem. Res., 27, 470-481 (1988)

18) Seibert, A.F., B.E. Reeves and J.R. Fair: Ind. Eng. Chem. Res., 29, 1901-1907 (1990)

19) Takishima, S., K. Saiki, K. Arai and S. Saito: J. Chem. Eng. Japan, 19, 48-56 (1986)

20) Wilke, C.R. and P. Chang: AIChE J., 1, 264-270 (1955) 